\title{
Special issue on recent advances in cognitive engineering
}

\author{
Chris Stary
}

Cognitive Engineering puts models of mental processes and cognitive systems into interaction practice, and at the same time seeks to explain phenomena, predict behavior, and develop schemes to process representations of cognitive models. This is complicated by social, emotional, and technical factors that are present in interactive settings. Consequently, researchers and practitioners in the area of cognitive engineering face the challenge to address these factors as well as the influence and context of technological artifacts themselves. This endeavor requires structured discourse on methodological and technical knowledge and findings across disciplines (cf. [1]).

As technology and technological artifacts have become abundant in everyday life, the design and evaluation of socio-technical aspects like situation-awareness, cognitive task analysis, work design, and the identification of common cognitive reference points are of crucial importance. Hence the role of stakeholders (designers, project managers, workers etc.) requires review, in particular, with respect to their informed involvement in development processes (cf. [2]). Their capabilities, including selforganized adaptation of artifacts and learning, are increasingly becoming essential for achieving certain qualities (cf. [3]), such as resilience of systems in diverse contexts of use.

Cognitive engineering can be seen as an academic and practical endeavor. Proponents of both areas operate out of different backgrounds, 'differences in defining and tackling problems - that prevail in the systems of science and practice' ([4], p. 517). These differences come into play when taking into account that 'communication elements of one system, such as science, cannot be authentically integrated into communication of other systems, such as the system of a business organization' (ibid., p. 516). For well-reasoned engineering processes adjusted knowledge from science and practice is required, in particular aligned

\footnotetext{
Correspondence: christian.stary@jku.at

Department of Business Information Systems - Communications Engineering,

JKU Knowledge Management Competence Center, Johannes Kepler
}

Universität Linz, Science Park III, Altenbergerstraße 69, 4040 Linz, Austria assumptions and mindsets behind specific development approaches (cf. [5, 6]). This adjustment is of particular importance when artifacts are created in collaborative settings (cf. [7]).

There are many ways to start and guide this process of development. In this issue, the inquiry of engineering knowledge in the course of system development is investigated. It allows practitioners to frame their acquisition of development knowledge and the identification of system requirements (cf. [5, 8]). Such an approach does not exclude generative developments, such as the on-site collaboration of research and development practice (cf. $[9,10])$.

The findings presented in this special issue on recent advances in cognitive engineering show the continuous need for analyzing concrete designs and implementations of cognitive models and their construction processes. Experiencing cross-disciplinary discourse in this way allows setting the stage for comprehensively informed and systemically analyzed research and development efforts. Discipline-specific approaches to cognitive engineering are challenged as they are likely to leave open essential questions of socio-technical system design. Instead, ways of working with cognitive systems and models in a sociotechnical context are identified fostering research and theory building.

The authors address several tensions associated with integrating various elements, including development assumptions, design dimensions, communication styles, rigor and relevance, and stakeholder interests, and show how such tensions are valuable themselves for research and theorizing (cf. $[2,11,12])$. The contributions reveal conflicting objectives, and practitioners' dilemmas. They describe the dialectical forces that foster the tensions associated with gaps, including studying specific phenomena, stakeholder involvement, and dedicated user support systems, namely for navigation and social relationships handling. In some cases the tensions represent fundamental, unresolvable paradoxes that can be generative of new research and practice if appreciated as such.

The contributions take different approaches on phenomena occurring in actual situations of using technical 
artefacts, such as presence, and providing models for more accurate representations and simulations of design (patterns), such as navigation in web-based systems. Each paper marks a milestone in terms of methodological development, because the respective research objectives could not have met using traditional appropriation of methods. In most of the articles the social dimension of design is examined, either referring to co-constructing interactive cognitive artefacts, or with respect to the context of use, serving a user community that needs to collaborate involving different occupational skills even in extreme situations, such as crises.

The discourse on methodological and technical knowledge and findings across disciplines has been structured according to studied phenomena and contexts of use. In their paper "The concept of "presence" as a measure for ecological validity in driving simulators' Christophe Deniaud, Vincent Honnet, Benoit Jeanne, and Daniel Mestre have used a pilot study to find a way measuring 'presence' as a proxy for ecological validity in drive simulators. They suggest measuring 'presence' through the 'attention' given to the driving task. In their study they used a dual task paradigm, adding the second task and oncoming traffic and analyzed behavioral measures of driving performance and individual 'presence'. The results indicate a lack of congruence between subjective and behavioral measures as well as behavioral differences in the various experimental conditions. The study is a promising start as more complex or top-down tasks in terms of controlled attention, cognitive involvement and emotions induced by media can be investigated based on the authors' results.

Herre van Oostendorp and Sonal Aggarwal focus on modeling and supporting navigation within a website. They propose a novel cognitive model for simulating navigation behavior based on the comprehension of deliberate searching and adequacy of paths and backtracking strategies. The result, based on an investigation of a mock-up websites, indicate performance enhancements for designs based on the proposed model compared to existing models. It appears that the new model supports greater efficiency when users perform multiple tasks in cognitively demanding situations. Moreover, the possibility exists to use the model for automated navigation support.

In their paper Salim Chujfi and Christoph Meinel identify patterns when exploring cognitive preferences and potential collective intelligence empathy for processing knowledge in virtual settings. They investigate virtual teams of teleworkers in organizations with respect to strategic innovations. The study focused on transformations through knowledge communication in distributed environments and non-interactive settings. Hereby, the channels are restricted, because gestures or mimics cannot be used and thus, direct feedback is hindered. The creation of knowledge is also restricted and its communication depends on involved stakeholders aggregating separately processed information and conveying it to others. In order to keep business operations running while promoting innovation, information allocation needs to be enriched with semantic analyses of the content and the social/individual context, including the social dynamics that emerge in virtual distributed settings.

Anke Dittmar and Laura Dardar investigated individual ecologies of calendar artifacts, where tasks, practices, artifact collections and users co-adapt and co-evolve. The authors investigated the web of activities shaping the individual calendar work through exploratory interviews and a follow-up study. In the latter the Day-Reconstruction Method has been exploited to account for the personal context and individual usage of calendar artifacts. The authors could demonstrate influence factor stemming from changing demands in everyday activities, the availability of new tools, and the participants' knowledge about the efforts and conceptions of calendar work. These factors influenced the willingness of users to explore and integrate new artifacts, and their deliberate non-use of technology. The results refer critically to scheduling appointments with high cognitive work load, and suggest a shift towards maintaining social relationships through calendar artifacts in technology-enriched settings.

Tilo Mentler and Michael Herzceg provide domainspecific insights in their paper 'Interactive cognitive artifacts for enhancing situation awareness of incident commanders in mass casualty incidents'. They investigated mass casualty incidents involving members of emergency medical service units. The authors point out the criticality of data required for assessing a certain situation accurately, and thus, the high skill demands on the acting stakeholders. Of particular importance are the modalities and media for communication conveying relevant knowledge on the situation. Interactive cognitive artifacts can improve situationspecific performance by exchanging and visualizing data in real-time, however, requiring role-and devicespecific adaptive designs, as the 2-year co-construction study reveals.

We are very grateful to the anonymous reviewers for their assistance and helpful comments. This special issue also benefited from comments at the presentations to the audience of the ECCE 2014 Conference on Cognitive Ergonomics at University of Vienna where most of the findings could be discussed. From then on, a process of mutual consultation has been triggered which seems to be help cross-disciplinary work due to its constructive nature (cf. [13]), and could serve as model for further transdisciplinary cognitive engineering developments. 
Received: 10 August 2015 Accepted: 11 August 2015

Published online: 28 August 2015

\section{References}

1. Kieser, A, \& Leiner, L. (2012). Collaborate with practitioners: But beware of collaborative research. J Manag Inq, 21, 14-28.

2. Nicolai, AT, Schulz, A, \& Göbel, M. (2011). Between sweet harmony and a clash of cultures: Does a joint academic-practitioner review reconcile rigor and relevance? J Appl Behav Sci, 47, 53-75.

3. Wasserman, IC, \& Kram, KE. (2009). Enacting the scholar-practitioner role: An exploration of narratives. J Appl Behav Sci, 45, 12-38.

4. Kieser, A, \& Leiner, L. (2009). Why the rigour-relevance gap in management research is unbridgeable. J Manag Stud, 46, 516-533.

5. Bartunek, JM. (1988). The dynamics of personal and organizational reframing. In R Quinn \& K Cameron (Eds.), Paradox and transformation: Toward a theory of change in organization and management (pp. 137-162). Cambridge, MA: Ballinger.

6. Beech, N, Maclntosh, R, \& MacLean, D. (2010). Dialogues between academics and practitioners: The role of generative dialogic encounters. Organ Stud, 31, 1341-1367.

7. Orr, K, \& Bennett, M. (2009). Reflexivity in the co-production of academicpractitioner research. Qual Res Organ Manag, 4, 85-102.

8. Briner, RB, \& Denyer, D. (2012). Systematic review and evidence synthesis as a practice and scholarship tool. In DM Rousseau (Ed.), Handbook of evidence-based management: Companies, classrooms and research (pp. 112-129). New York: Oxford University Press.

9. Amabile, TM, Schnatzel, EA, Moneta, GB, \& Kramer, SJ. (2006). Leader behaviors and the work environment for creativity: Perceived leader support. Leadersh Q, 15, 5-32.

10. Avenier, M, \& Parmentier Cajaiba, AC. (2012). The dialogical model: Developing academic knowledge for and from practice. Eur Manag Rev, 9, 199-212.

11. Mohrman, SA, \& Lawler, EE (Eds.). (2011). Useful research: Advancing theory and practice. San Francisco: Berrett-Koehler.

12. Ospina, SM, \& Dodge, J. (2005). It's about time: Catching method up to meaning-The usefulness of narrative inquiry in public administration research. Public Adm Rev, 65, 143-157.

13. Schein, EH. (1999). Process consultation revisited: Building the helping relationship. Reading, MA: Addison-Wesley.

\section{Submit your manuscript to a SpringerOpen ${ }^{\circ}$ journal and benefit from:}

- Convenient online submission

- Rigorous peer review

- Immediate publication on acceptance

- Open access: articles freely available online

- High visibility within the field

- Retaining the copyright to your article

Submit your next manuscript at $>$ springeropen.com 